\title{
WAGE PROBLEMS IN INDONESIA IN THE HUMAN RIGHTS PERSPECTIVE (CASE OF INAPPROPRIATE WAGES FOR POT WORKERS IN TANGERANG)
}

\author{
Zahra Zara Mahasin \\ Institute for Labor and Justice Semarang \\ Firqotun Naziah \\ Institute for Labor and Justice Semarang \\ Ridwan Arifin \\ Faculty of Law, Universitas Negeri Semarang \\ Email: zahramahasin@gmail.com
}

\begin{abstract}
This paper analyzes the fulfillment of rights for workers in the case in Tangerang (fulfillment of a decent salary). Whereas, one form of the implementation of the mandate of the 1945 Constitution in realizing decent livelihoods, especially for workers, is the minimum wage policy based on Law No. 13 of 2003 concerning Manpower which aims to provide protection for workers and their families, this is stated by clear in consideration of letter (d) of Law Number 13 of 2003 concerning Manpower, namely that the protection of labor is intended to guarantee the basic rights of workers and guarantee equal opportunity and treatment without discrimination on any basis to realize the welfare of workers and their families with still pay attention to the development progress of the business world. The disharmony in employment relations or labor turmoil is mostly caused by wage problems that are felt to be still very low. The low level of wages in Indonesia is caused by the abundant supply of labor, the level of labor skills is very low, and the government has an interest and seeks to create and expand employment opportunities.
\end{abstract}

Keywords: Wage; Human Rights; Workers Protection; Labor Problems

The authors wish to thank Rasdi and Sonny Saptoajie Wicaksono for helpful comments on an earlier draft of this paper. The paper basically developed from the research report on Human Rights course on Faculty of Law Universitas Negeri Semarang (2018-2019) and collaborate with some study centers and Human Rights NGOs.

The Indonesian Journal of International Clinical Legal Education DOI: 10.15294/ijicle.v2il.37326

https://journal.unnes.ac.id/sju/index.php/iccle

C 2020 Authors. This work is licensed under a Creative Commons Attribution-

ShareAlike 4.0 International License. All writings published in this journal are personal views of the authors and do not represent the views of this journal and the author's affiliated institutions.

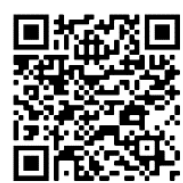




\section{PENDAHULUAN}

Buruh menurut kamus bahasa Indonesia adalah orang yang bekerja untuk orang lain dengan mendapat upah. Buruh adalah setiap orang yang bekerja dengan menerima upah atau imbalan dalam bentuk lain. Dengan dipadankannya istilah pekerja dengan buruh merupakan kompromi setelah dalam kurun waktu yang amat panjang dua istilah tersebut bertarung untuk dapat diterima oleh masyarakat. ${ }^{1}$

Pada jaman feodal atau jaman penjajahan Belanda dahulu yang dimaksudkan buruh adalah orang-orang pekerja kasar seperti kuli, tukang, dan lain-lain. Orang-orang ini oleh pemerintah Belanda dahulu disebut dengan blue collar (berkerah biru), sedangkan orang-orang yang mengerjakan pekerjaan halus seperti pegawai administrasi yang bisa duduk dimeja di sebut dengan white collar (berkerah putih). Dalam perkembangan hukum perburuhan di Indonesia, istilah buruh diupayakan untuk diganti dengan istilah pekerja. ${ }^{2}$

Khusus tentang upah bagi pekerja/buruh pabrik seolah selalu menjadi permasalahan rutin setiap tahunnya yang tidak kunjung selesai dan selalu memberikan dampak yang cukup luas, baik bagi pekerja/buruh dan pengusaha pada khususnya serta bagi masyarakat pada umumnya Salah satu dampak yang setiap tahun muncul adalah adanya unjuk rasa (demontrasi) yang dilakukan oleh pekerja/buruh dalam memperjuangkan haknya untuk mendapatkan upah, sebagai sarana untuk memenuhi kebutuhan hidup bagi pekerja/buruh dan keluarganya. ${ }^{3}$

Implementasi amanah UUD 1945 dalam mewujudkan penghidupan yang layak, khususnya bagi pekerja/buruh, maka pemerintah membuat kebijakan upah minimum berdasarkan UndangUndang Nomor 13 Tahun 2003 Tentang Ketenagakerjaan yang bertujuan untuk memberikan perlindungan bagi tenaga kerja dan keluarganya, hal tersebut dinyatakan dengan jelas dalam konsideran huruf (d) UU Nomor 13 Tahun 2003 Tentang Ketenagakerjaan yaitu bahwa perlindungan terhadap tenaga kerja dimaksudkan untuk menjamin hak-hak dasar pekerja/buruh dan menjamin kesamaan kesempatan serta perlakuan tanpa diskriminasi atas dasar apapun untuk mewujudkan kesejahteraan pekerja/buruh dan keluarganya dengan tetap memperhatikan perkembangan kemajuan dunia usaha.

Dalam Undang-Undang Nomor 13 Tahun 2003 Tentang Ketenagakerjaan, Pasal 1 butir 30 dinyatakan: "Upah adalah hak pekerja/buruh yang diterima dan dinyatakan dalam bentuk uang sebagai imbalan dan pengusaha atau pemberi kerja kepada pekerja/buruh yang

1 Uwiyono, Aloysius., dkk. Asas-Asas Hukum Perburuhan. Jakarta: PT. RajaGrafindo Persada. 2014. hlm. 90.

2 Kartasapoetra, g. dan Rience Indraningsih, Pokok-pokok Hukum Perburuhan. Cet. 1. Bandung: Armico Bandung.1982. hlm 75.

3 Widyawati, Anis. "Kajian Hukum Internasional Terhadap HAM". Jurnal Ilmu Hukum Pandecta Vol. 2, No. 2. 2008. hlm 80. 
ditetapkan dan dibayarkan menurut suatu perjanjian kerja, kesepakatan, atau peraturan perundang-undangan, termasuk tunjangan bagi pekerja/buruh dan keluarganya atas suatu pekerjaan dan/atau jasa yang telah atau akan dilakukan.

Ketidak harmonisan dalam hubungan ketenagakerjaan atau gejolak ketenagakerjaan sebagian besar ditimbulkan oleh permasalahan upah yang dirasakan masih sangat rendah. Rendahnya tingkat upah di Indonesiadisebabkan persediaan tenaga kerja sangat melimpah, tingkat ketrampilan buruh sangat rendah,serta pemerintah yang berkepentingan dan berupaya menciptakan serta memperluas kesempatan kerja.

\section{PROBLEMATIKA PENGUPAHAN DI INDONESIA}

Upah minimum propinsi (UMP) atau upah minimum kabupaten (UMK) sering diistilahkan dengan upah minimum. Upah ini pada prinsipnya diberikan kepada buruh sebagai jaringan pengaman (safety net). Diharapkan upah minimum dapat berperan sebagai jaringan pengaman agar buruh tidak dieksploitasis, sehingga buruh mempunyai penghidupan yang cukup layak bagi dirinya dan keluarganya. Oleh karena itu upah minimum hanya diterapkan kepada buruh yang masa kerjanya dibawah 1 tahun.

Sedangkan buruh dengan masa kerja diatas satu tahun upah ditetapkan sesuai dengan hasil perundingan bipartit antara pengusah dengan serikat buruh. Namun pada praktiknya, upah minimum juga diberikan kepada buruh yang telah mempunyai masa kerja diatas satu tahun. Hal ini bertentangan dengan pasal 14 Pemenakertrans No per01/MEN/1999 tentang Upah minimum:

"(1) bagi buruh yang berstatus tetap, tidak tetap, dan dalam masa percobaan, upah diberikan oleh pengusaha serendah-rendahnya sebesar upah minimum. (2) upah minimum hanya berlaku bagi buruh yang mempunyai masa kerja kurangdari l(satu) tahun".

Kebijakan upah minimum saat inGi yan diterapkan oleh Gubernur masih berkutat pada upah minimum, dengan besaran nilai masih jauh dari kehidupan layak bagi buruh dan keluarganya. ${ }^{4}$

Mencermati beberapa teori yang telah diuraikan sebelumnya, kebijakan pengupahan diIndonesia lebih pada merupakan perpaduan konsep-konsep pengupahan tersebut. Ini disebabkan kompleksitas permasalahan pengupahan, seperti pertama, adanya tingkat upah yang masihberada dibawah standar kebutuhan fisik minimum; kedua, adanya perbedaan upah yang terlalumencolok baik antar daerah, antar sektor

$4 \quad$ Abdul hakim. Aspek hukum pengupahan berdasarkan UU No 13 tahun 2003. Bandung: PT Citra Aditya Bakti, 2006, hlm. 24 
maupun subsektor dan ketiga, adanya kesenjangan yangterlalu mencolok antara besarnya upah tertinggi dengan upah terendah yang diterima pekerja. Perbedaan ini terjadi baik secara daerah, sektor maupun subsektor sehingga akibatnya muncul kesenjangan upah rasio upah. ${ }^{5}$

Padahal dengan ketelibatan negara (Gubernur) di dalam penetapan upah, diharapkan dapat mengarahkan pengusaha untuk mengeluarkan kebijakan upah minimum yang menguntungkan buruh. Dengan kata lain kebijakan upah minimum belum berpengaruh secara signifikan terhadap peningkatan pendapatan buruh, apalagi situasi ekonomi lesu, membuat pemenuhan kebutuhan hidup semakin berat. Disamping itu, penggunaan sistem kontrak dan outsourcing berdampak buruk pada sistem pengupahan yang adil. Kalau pun ada kenaikan upah minimum setiaptahun, tidak pernah memadai untuk mencapai kebutuhan layak buruh dan keluarganya. Karena pemerintah selalu gagal dalam menekan dan menstabilkan harga kebutuhan hidup.

Kondisi anomali kebijakan pengupahan yang tidak hanya terjadi pada buruh dengan masa kerja dibawah 1 (satu) tahun, tetapi juga buruh dengan masa kerja diatas 1 (satu) tahun. Secara yuridis melanggar permenakertrans No. 01/MEN/1999 Pasal 25 ayat (1), pengusaha yang melanggar dan tidak memnuhi ketentuan dalam Pasal 14 ayat (1) dan (2) dipidana dengan pidana kurungan selama lamanya 3 (tiga) bulan atau denda setinggi-tingginya Rp 100.000,00 (seratus ribu rupiah).

Pembayaran upah buruh dibawah upah minimum sebagaimana ditetapkan pleh Gubernur setiap tahunnya sangat tidak menguntungkan buruh, terutama bagi buruh yang bekerja disektor informal. Karena upah atau gaji yang tidak sesuai dengan standar yang ditetapkan UU No. 13 tahun 2003.

Upah buruh yang tidak sesuai dengan standar UMP sdan UMK sangat dilarang keras oleh Pasal 90 ayat (1) UU No. 13 Tahun 2003 yang menegaskan bahwa "pengusaha dilarang membayar upah lebih rendah dari upah minimum..." kondisi demikian tentunya sangat merugikan kehidupan buruh dan keluarganya yang dengan upah minimum saja tidak mampu memenuhi kehidupannya baik itu makanan dan minuman, sandang, perumahan, pendidikan, kesehatan, rekreasi, maupun jaminan hari tua.

Kondisi itu tentu erat kaitannya dengan pemahaman terhadap "hubungan industrial" yang dimiliki oleh sebagian besar hanya mengejar keuntungan semata-mata (profit oriented) tanpa memikirkan penghidupan buruh dan keluarganya.

Pembayaran upah buruh dibawah UMP, jelas sangat bertentang dengan ketentuan Pasal 88 ayat (1) UU No. 13 meroleh penghasilan yang memenuhi penghidupan yang layak bagi kemanusiannya, upah tersebut tidak hanya memenuhi ketentuan upah minimum dalam UMP, tetapi juga

5 Prijono Tjiptoherijanto, Perkembangan Upah Minimum dan Pasar Tenaga Kerja, Analisis CSIS, tahun XXIII, No. 3, Mei-Juni 1994, hlm. 228 
penghasilannya dari bekerja mampu kebutuhan hidupnya dan keluarganya sesuai kebutuhan masyarakat pada umumnya.

Sesungguhnya Pasal 185 ayat (1) dan (2) UU No. 13 Tahun 2003 secara gamblang melarang pembayaran upah dibawah upah minimum, yang termasuk kualifikasi tindak pidana kejahatan yang berbunyi: "Barang siapa melanggar ketentuan sebagaimana dimaksud dalam...Pasal 90 Ayat (1)...dikenakan sanksi pidana penjara paling singkat 1 (satu) tahun dan paling lama 4 (empat) tahun dan/atau denda paling sedikit Rp.100.000.000,- (seratus juta rupiah) dan palng banyak Rp. 400.000.000,- (empat ratus juta rupiah)".

Meskipun "Pelanggaran upah minimum" kerap kali dilakukan pengusaha, disnaker sebagai institusi yang bertanggung jawab dalam melakukan pengawas dan penyidik tidak melakukan tindakan "judical" seperti, investigasi, penyelidikan dan penyidikan. Alasan pengawas dan penyidik adalah Disnaker secara institusional tidak didukung oleh sumber daya manusia yang cukup dan kapabel, anggaran, cakupan lingkup tugas yang luas ditambah lagi perangkat hukum yang tidak memadai, dan intervensi politik kepala daerah, serta konspirasi pengawas/penyidik dengan pengusaha.

Tindakan itu sesungguhnya merupakan bentuk eksploitasi terhadap buruh, yang tidak hanya berhenti sampai disitu, dimana pengusaha juga kerap kali tidak membayar atau memenuhi upah buruh, sementara buruh sudah melaksanakan kewajibannya, yang secara yuridis pengusaha seharusnya menunaikan kewajibannya, namun tidak demikian justru UU No. 2 Tahun 2004 membuka ruang bagi buruh untuk mengajukan "complaint" ke pengadilan hubungan industrial untuk mendapatkan haknya. Padalah mekanisme itu memperluas proses panjang dan melelahkan.

Tidak dipenuhinya upah, sebenarnya secara tugas dilarang di dalam Pasal 186 ayat (1) UU No 13 Tahun 2003 yang menegaskan bahwa "barang siapa melanggar ketentuan...pasal 93 ayat (2)...dikenakan sanksi pidana penjara paling singkat 1 (satu) bulan dan paling lama 4 (empat) tahun dan/atau denda paling sedikt Rp. 10.000.000,- (sepuluh juta rupiah) dan paling banyak Rp. 400.000.000,- (empat ratus juta rupiah)

Dalam beberapa kasus yang dialami buruh, ketentuan Pasal 93 ayat (1) dan (2) UU No. 13 Tahun 2003 kerap dijadikan pintu masuk pengusaha menghentikan upah buruh yang notabene telah bekerja, tanpa ada tindakan represif dari pengawas/penyidik. Seharusnya menurut ketentuan Pasal 155 UU No. 13 Tahun 2003 selama putusan maupun buruh harus tetap melaksanakan segala kewajibannya.

Terjadinya pelanggaran hak-hak normatif buruh seperti pembayaran upah dibawah UMP atau pun upah tidak dibayarkan sesungguhnya merupakan "affirmasi" lemahnya kinerja pengawas/penyidik ketenagakerjaan bertugas untuk menjamin penegakan ketentuan UU No 13 Tahun 2003 sehingga hubungan industrial dapat berjalan secara proporsional dan demokratis. Berikut akan dipaparkan tabel upah minimum provinsi seluruh Indonesia. 
Tabel 1 Upah Minimum Provinsi Indonesia

\begin{tabular}{|c|c|c|c|}
\hline \multirow{2}{*}{ Provinsi } & \multicolumn{3}{|c|}{ Tahun } \\
\hline & 2014 & 2015 & 2016 \\
\hline Aceh & 1750.000 & 1900.000 & 2185.500 \\
\hline Sumatera Utara & 1505850 & 1625000 & 1811875 \\
\hline Sumatera Barat & 1490000 & 1615000 & 1800725 \\
\hline Riau & 1700.000 & 1878000 & 1878000 \\
\hline Jambi & 1502300 & 1710000 & 1906650 \\
\hline Sumatera Selatan & 1825000 & 1974346 & 2206000 \\
\hline Bengkulu & 1350000 & 1500000 & 1605000 \\
\hline Lampung & 1399037 & 1581000 & 1763000 \\
\hline $\begin{array}{l}\text { Kep Bangka } \\
\text { Belitung }\end{array}$ & 1640000 & 2100000 & 2341500 \\
\hline Kep Riau & 1665000 & 1954000 & 2178710 \\
\hline Dki Jakarta & 2441000 & 2700000 & 3100000 \\
\hline Jawa Barat & 1000000 & 1000000 & 2250.000 \\
\hline Jawa Tengah & 910.000 & 910.000 & - \\
\hline DIY Yogyakarta & 988.500 & 988.000 & - \\
\hline Jawa Timur & 1.000 .000 & 1000.000 & - \\
\hline Banten & 1325000 & 1600.000 & 1784000 \\
\hline Bali & 1542600 & 1621172 & 1807600 \\
\hline $\begin{array}{l}\text { Nusa Tenggara } \\
\text { Barat }\end{array}$ & 1.210 .000 & 1330.000 & 1482950 \\
\hline $\begin{array}{l}\text { Nusa Tenggara } \\
\text { Timur }\end{array}$ & 1.150 .000 & 1250.000 & 1.425 .000 \\
\hline Kalimantan Barat & 1.380 .000 & 1560.000 & 1739.400 \\
\hline $\begin{array}{l}\text { Kalimantan } \\
\text { Tengah }\end{array}$ & 1723970 & 1896367 & 2057558 \\
\hline $\begin{array}{l}\text { Kalimantan } \\
\text { Selatan }\end{array}$ & 1.620 .000 & 1870000 & 2085050 \\
\hline Kalimantan Timur & 1886315 & 2026126 & 2161253 \\
\hline Kalimantan Utara & - & 2026126 & 2175340 \\
\hline Sulawesi Utara & 1900000 & 2150000 & 2400.000 \\
\hline
\end{tabular}




\begin{tabular}{lccc}
\hline Sulawesi Tengah & 1250000 & 1500.000 & 1670000 \\
\hline $\begin{array}{l}\text { Sulawesi Selatan } \\
\begin{array}{l}\text { Sulawesi } \\
\text { Tenggara }\end{array}\end{array}$ & 1800000 & 2000.000 & 2250.000 \\
\hline Gorontalo & 1325000 & 1600000 & 1875000 \\
\hline Sulawesi Barat & 1400000 & 1.655 .500 & 1864000 \\
\hline Maluku & 1415000 & 1650000 & 1775000 \\
\hline Maluku Utara & 1440746 & 1577617 & 1681266 \\
\hline Papua Barat & 1870000 & 2015000 & 2237000 \\
\hline Papua & 2040000 & 2193.000 & 2435000 \\
\hline Indonesia & 1584391 & 1790342 & 1997819 \\
\hline
\end{tabular}

\section{INTERVENSI PEMERINTAH DI BIDANG PENGUPAHAN}

Dalam dunia kerja, pemberian upah pada umumnya selalu mempertimbangkan kemampuan pekerja yang tercermin dalam produktifitas kerja. Pemerintah melakukan intervensi karena sangat berkepentingan untuk menyelaraskan antara upah yang memenuhi penghidupan yang layak bagi kemanusiaan dan pencapaian produktivitas kerja yaitu dengan memerhatiakn:

a) kebutuhan hidup pekerja

b) kesenjangan sosial

c) Prestasi kerja

d) Nilai kemanusiaan dan harga diri ${ }^{6}$

Oleh karena itu, pemerintah memberlakukan kebijakan penetapan upah minimum yang tadinya dilndasi kebutuhan fisik minimum (KFM) berkembang menjadi kebutuhan hidup minimum (KHM), berlaku secara mikro-regional dengan maksud:

1. Sebagai jaringan pengaman

2. Sebagai sarana untuk meningkatkan taraf hidup kelompok terendah

3. Sebagai alat terjadinya pemerataan pendapatan, dan

4. Pemberian upah atas upah minimum diataur secara internal di perusahaan

Kebijakan pemerintah dibidang pengupahan dilatar belakangi oleh permasalahan pengupahan yang selalu muncul yang dipicu terjadinya konflik kepentingan antara pengusaha dan pekerja.msalag pokok pengupana meliputi:

1. rendahnya upah bagi pekerja bawah

2. kesenjangan upah terendah dan tertinggi

3 . bervariasinya komponen upah

6 Asikin, Zainal., dkk. Dasar-dasar Hukum Perburuhan. Jakarta: PT. RajaGransindo Persada. 2012. 
4. tidak jelasnya hubungan antara upah dan produktivitas

Rendahnya upah bagi pegawai bawah sangat dirasakan pekerja tetapi sulit dideteksi oleh pengawas ketenagakerjaan dalam rangka penerapan upah minimum. Bagi pekerja formal mungkin lebih mudah dideteksi, akan tetapi bagi pekerja informal akan sulit bila tidak ada laporan dari masyarakat atau pekerja. Sedangkan kesenjangan antara upah terendah pekerja dengan upah tertinggi pimpinan perusahaan telah terjadi di tingkat regional maupun nasional dapat memicu kecemburuan sosial. Selain itu, pemberian upah dalam bentuk komponen-komponen pengupahan masih banyak yang membingungkan pekerja bila dikaitkan dengan kebijakan pemberian upah minimum, dan demikian juga dikenakan upah berdasarkan penelitian kinerja sangat kurang dimengerti oleh pekerja karena kurangnya sosialisasi.

\section{ANALISIS HAK ASASI MANUSIA DALAM KASUS BURUH PANCI}

\section{Kronologi Kasus Buruh Panci di Tangerang}

Direktori Putusan Mahkamah Agung Republik Indonesia PUTUSAN Nomor: 40/ PID/ 2014/ PT.BTN. Perbuatan tersebut berawal dari adanya perintah Terdakwa Yuki Irawan Bin Suharjo Susilo selaku pemilik CV. Cahaya Logam kepada Usman dan Topik (masing-masing DPO) pada sekitar Bulan september 2012 untuk mencari karyawan baru guna dipekerjakan di pabrik pembuatan kuali miliknya di Kampung Bayur Opak Rt 003 Rw 006 Desa Lebak Wangi Kecamatan Sepatan Kabupaten Tangerang, Atas perintah dari Terdakwa tersebut, Usman pergi ke daerah Cianjur Jawa Barat untuk mencari karyawan baru di pabrik kuali milik Terdakwa, Usman kemudian mendatangi orang-orang yang mau bekerja, dengan mengatakan bahwa mereka akan dipekerjakan di pabrik timah di Tangerang-Banten dengan iming-iming gaji sebesar Rp. 500.000.- (lima ratus ribu rupiah) per bulan dan setelah bekerja selama 6 (enam) bulan gaji akan dinaikan menjadi Rp. 1.500.000.- (satu juta lima ratus ribu rupiah) perbulannya, mendapatkan bonus serta uang lembur, diberi makanan yang enak, rokok diberi satu bungkus perhari, tinggal di mess karyawan yang bersih dan setiap 1 (satu) kamar mess berisi 3 (tiga) orang serta diberikan hak berlibur pada hari Minggu, yaitu Dede Darussalam, Abdul Nawafikri, Saipul Anwar, Rahmat Nugraha, Nuryana, Didin Sadinar, Sukaedi, Bagas, Uwoh Abdullah, Dirman alias Dira, Enceng alias Aceng, Nuryaman, Rahmat Bin Hasan, Junaidi, Irwan alias Iwan Bin Ade Emat, Gin Gin.

Bahwa atas iming-iming tersebut, orang-orang yang didatangi oleh Usman sebagaimana tersebut di atas tertarik dan bersedia untuk menjadi karyawan pabrik. Sedangkan Topik pergi ke daerah Lampung untuk mencari karyawan baru guna dipekerjakan di pabrik kuali milik Terdakwa, Topik lalu mengajak orang-orang untuk bekerja di 
Tangerang-Banten dengan iming-iming gaji sebesar Rp. 700.000.- (tujuh ratus ribu rupiah) per bulan dan setelah kontrak selama 6 (enam) bulan, maka gaji akan dinaikan menjadi Rp. 1.500.000.- (satu juta lima ratus ribu rupiah) perbulannya, mendapatkan uang lembur, diberi makanan yang enak, rokok diberi satu bungkus perhari, tinggal di mess karyawan yang bersih dan setiap 1 (satu) kamar mess berisi. 3 (tiga) orang serta setiap 3 (tiga) hari sekali diajak liburan ke Pantai Ancol, yaitu : Andi Gunawan, Arif Udin, Herfansyah, Iwan Kurniawan, Adi Putra, Misyanto, Rizal Putra, Junaidi.

Selanjutnya karyawan-karyawan yang telah direkrut tersebut di bawa ke lokasi pabrik dan setelah sampai di lokasi pabrik pembuatan kuali milik Terdakwa di di Kampung Bayur Opak Desa Labak Wangi Kecamatan Sepatan Kabupaten Tangerang, ternyata apa yang didapat dan dialami para pekera tersebut di atas tidak seperti yang diimingimingkan. Pada kenyataannya Terdakwa memasukan 24 (dua puluh empat) orang karyawan yang baru dikumpulkannya tersebut ke dalam sebuah ruangan kamar (mess) ukuran $3 \mathrm{~m}$ x 4m, dengan kondisi ruangan yang lembab, kurang ventilasi udara, tidak terdapat tempat tidur dan lantai beralaskan karpet plastik dengan hanya difasilitasi berupa TV 14 inci, kipas angin dan sebuah kamar mandi.

Bahwa setelah semua pekerja dimasukan ke dalam ruangan kamar tersebut, selanjutnya Tedi Sukarno mengambil barang-barang milik pekerja berupa baju, hand phone, dompet, sepatu serta uang dan hanya meninggalkan pakaian yang melekat pada badan pekerja dengan alasan agar tidak hilang, lalu barang-barang tersebut diserahkan kepada Terdakwa, dan sejak saat itu para pekerja tidak pernah mengganti pakaiannya dari mulai masuk bekerja.

Bahwa setiap hari para pekerja diharuskan untuk bekerja mulai dari jam 05.30 Wib sampai dengan jam 20.00 Wib bahkan sering hingga jam 22.00 Wib tanpa ada batas waktu yang tetap dan tidak pernah ada hari libur. Bahwa pada setiap malam secara bergantian Tedi Sukarno, Nurdin,Sudirman dan Roh Jaya bertugas menggiring para pekerja dari tempat bekerja dengan cara berbaris satu persatu lalu memasukannya ke dalam ruangan kamar mess, setelah itu pintu kamar mess dikunci dari luar serta dijaga dan pada setiap pagi harinya sekitar jam $05.00 \mathrm{Wib}$ pintu kamar mess dibuka dan para pekerja tersebut dibangunkan dengan cara mengedor-ngedor pintu kamar mess Bahwa untuk mengejar target produksi kuali, Terdakwa acap kali melakukan pemukulan terhadap pekerja pabrik, yaitu Saipul Anwar, Rahmat Nugraha, Iwan Kurniawan, Bagas, Uwoh Abdulah, Nuryaman dan juga telah memerintahkan Tedi Sukarno, Nurdin, Sudirman dan Roh Jaya untuk melakukan pemukulan terhadap para pekerja yang lambat saat bekerja, membuat kesalahan saat bekerja dan yang berusaha melarikan diri, yaitu Andi Gunawan Bin Agustabi, Dirman alias Dira, Rahmat Hidayat, Arif Udin, Junaidi, Bagas, Herfansyah, Irwan, Nuryana. Disamping melakukan pemukulan terhadap para karyawan pabrik, Terdakwa dan Tedi Sukarno, Nurdin, Sudirman serta Roh Jaya juga melakukan pengancaman kepada para pekerja supaya 
tidak melarikan diri, sehingga para pekerja menjadi ketakutan dan tidak berani melawan dan para pekerja pun tidak diperbolehkan ke luar lokasi pabrik untuk bersosialisasi dengan masyarakat, tidak diperbolehkan untuk menghubungi keluarganya, bahkan tidak diberikan hak untuk melaksanakan ibadah.

Kondisi yang dialami para pekerja tersebut membuat para pekerja ketakutan dan terkekang. Bahwa Terdakwa mengharuskan para pekerja untuk membuat panci dengan cara grenjeng dibakar untuk memisahkan bahan dasar almunium dengan plastik, aluminium hasil pemisahan dimasukan ke dalam sebuah drum lalu dicampur dengan grehon (bahan yang berwarna hitam putih sebesar batu kali yang barbau menyengat) untuk dibakar, selanjutnya isi drum diaduk dengan menggunakan pipa sampai menjadi cairan panas dan berbau menyengat, kemudian cairan panas tersebut diangkat dengan menggunakan gayung dan dimasukan ke dalam cetakan berbentuk balok ukuran $60 \mathrm{~cm}$ x $10 \mathrm{~cm}$ tebal $5 \mathrm{~cm}$ yang diolesi kapur, setelah menunggu selama lebih kurang 2 (dua) menit, almunium menjadi keras, kemudian diangkat dengan menggunakan dua batang besi dan disusun sampai 50 (lima puluh) balok.

Setelah balok almunium berjumlah 100 (seratus) buah, kemudian balokan tersebut dimasukan ke dalam 1 (satu) sibel (drum besar setinggi $1 \mathrm{~m}$ ). lalu dipanaskan dengan cara dibakar dengan menggunakan kayu, setelah balokan tersebut mencair, kemudian cairan tersebut dicampur dengan foil ukuran panjang $1 \mathrm{~m}$ dan lebar $30 \mathrm{~cm}$, diaduk sampai meleleh. Selanjutnya cairan panas tersebut diangkat dengan menggunakan gayung lalu dipindahkan ke cetekan kuali yang terbuat dari tanah liat, setelah 2 (dua) menit cairan almunium tersebut mulai berbentuk kuali lalu disusun dan ditimbang. Pada keesokan harinya kuali tersebut digerinda, dikikir dan dibubut dengan alat hingga menjadi rapi. Kuali yang sudah jadi di bawa ke gudang lalu di beri stempel/cap berupa tulisan dan gambar bintang Jerapah, Banteng, Arwana dan kuali siap untuk dipasarkan.

Bahwa selama berada di lokasi pabrik kuali dan melakukan pekerjaan pembuatan kuali, para pekerja menerima perlakukan yang sewenang-wenang dari Terdakwa serta Tedi Sukarno, Nurdin, Sudirman dan Roh Jaya dan Terdakwa tidak menepati apa yang dijanjikan kepada ke-24 (dua puluh empat) orang pekerja pabriknya, melainkan Terdakwa melakukan tindakan kerja paksa dan memanfaatkan fisik para pekerja tersebut untuk mengejar target produksinya sebanyak 200 kuali perhari dan mendapatkan keuntungan secara sepihak. Perbuatan Terdakwa Yuki Irawan sebagaimana diatur dan diancam pidana dalam Pasal 2 ayat (1) Undang-Undang Nomor 21 Tahun 2007 tentang Pemberantasan Tindak Pidana perdagangan Orang Jo Pasal 55 ayat (1) ke-1.

Terdakwa juga mempekerjakan buruh anak-anak antara lain: Ajat suderajat berumur 16 Tahun, Usup Berumur 17 Tahun, Doa Supiandi berumur 16 tahun, Budi berumur 17 tahun, Rahmat Hidayat berumur 17 Tahun dan Dik Dik Sugianto berumur 17 tahun. Buruh anak-anak tersebut pun diperlakukan sama dengan buruh yang lain. Yuki selaku 
terdakwa dalam putusannya di vonis 11 tahun penjara dan denda Rp 500 subsider kurungan 3 bulan penjara.

\section{Hak-Hak Yang Dilanggar dalam Kasus Buruh Panci Perspektif Hak Asasi Manusia}

Di dalam Undang-Undang ini setidaknya ada 3 pasal yang dilanggar yaitu:

a. Pasal 20

(1) Tidak seorang pun boleh diperbudak atau diperhamba.

(2) Perbudakan atau perhambaan, perdagangan budak, perdagangan wanita,dan segala perbuatan berupa apapun yang tujuannya serupa, dilarang.

b. Pasal 33

(1) Setiap orang berhak untuk bebas dari penyiksaan, penghukuman atau perlakuan yang kejam, tidak manusiawi, merendahkan derajat dan martabat kemanusiaannya.

c. Pasal 36

2) Tidak seorang pun boleh dirampas miliknya dengan sewenangwenang dan secara melawan hukum. Pasal 36 Ayat (2) ini sehubungan dengan pengakuan korban bahwa handphone dan dompet para buruh disita/dirampas sehingga mereka tidak bisa berkomunikasi dengan keluarga atau teman.

Kejadian tersebut telah melanggar prinsip-prinsip dari Hak Azasi Manusia (HAM) dan juga aturan-aturan yang ada dalam Undang-undang Ketenagakerjaan terkait waktu kerja, keselamatan dan kesehatan kerja serta pengupahan. Peristiwa tersebut juga melanggar Undang-undang Perlindungan Anak dimana beberapa anak dibawah umur dipaksa bekerja di pabrik tersebut. Dalam UU Ketenagakerjaan Pasal 86 Ayat (1) disebutkan: Setiap pekerja/buruh mempunyai hak untuk memperoleh perlindungan atas:

a. keselamatan dan kesehatan kerja;

b. moral dan kesusilaan; dan

c. perlakuan yang sesuai dengan harkat dan martabat manusia serta nilai-nilai agama.

Dari kitab undang-undang warisan Belanda ini setidaknya ada 2 pasal yang dilanggar yaitu Pasal 333 Ayat (1) tentang perampasan kemerdekaan diancam dengan pidana penjara maksimal 8 (delapan) tahun. Dan yang kedua yaitu melanggar Pasal 351 Ayat (1) tentang penganiayaan, diancam dengan pidana penjara maksimal 2 tahun 8 bulan

Pada pasal 27 ayat 2 UUD 1945 menyebutkan bahwa "Tiap-tiap warga negara berhak atas pekerjaan dan penghidupan yang layak bagi kemanusiaan. Pasal tersebut mencerminkanbahwa ada jaminan ataspenghidupan yang layak bagi kemanusiaan, sehingga sangat wajarsegala bentuk pengupahan juga harus diupayakan memperoleh jaminan tersebut. Konsepsi demikian juga menjadi dasar perubahan 
dalam penentuan upah minimum, dari kebutuhan Fisik Minimum (KFM) menjadi Kebutuhan Hidup Minimum (KHM).

Di dalam Pasal 88 Ayat (1) UU Ketenagakerjaan disebutkan bahwa setiap pekerja/buruh berhak memperoleh penghasilan yang memenuhi penghidupan yang layak bagi kemanusiaan. Dalam kasus ini, jangankan penghasilan yang layak, kenyataan di lapangan bahwa para pekerja tidak digaji. Selain itu keselamatan pekerja juga sangat rendah sekali dengan adanya kasus perbudakan ini.

Kasus perbudakan ini telah menambah problema-problema ketenagakerjaan di Indonesia. Pada saat buruh dan pekerja selalu merayakan May Day (Hari Buruh se-Dunia yang jatuh setiap tanggal 1 Mei) untuk menuntut hak-hak mereka agar dapat hidup yang layak - dan ini belum terpenuhi, di sisi lain masih terdapat kasus-kasus perbudakan terhadap para pekerja/buruh ini. Masalah perbudakan ini seharusnya hanya terjadi di zaman kegelapan (jahilliyah) silam, tetapi perbudakan ini masih terjadi di era modernisasi saat ini. ${ }^{7}$

Lalu, dalam konteks perlindungan HAM, kasus perbudakan ini telah melanggar HAM baik dari sisi instrumen Hukum Internasional maupun instrumen Hukum Nasional. Di dalam instrumen Hukum Internasional, terdapat International Covenant on Civil and Political Rights (ICCPR) atau Kovenan Internasional tentang Hak Sipil dan Politik tahun 1966 yang telah diratifikasi oleh Indonesia melalui Undangundang nomor 12 Tahun 2005 tentang Pengesahan Kovenan Internasional Hak Sipil dan Politik ini.

Di dalam pasal kovenan ini, terdapat pasal yang menyatakan hak setiap manusia untuk bebas dari perbudakan dan kerja paksa. Pasal 6 angka 1 kovenan ini menyatakan bahwa setiap manusia berhak atas hak untuk hidup yang melekat pada dirinya. Hak ini wajib dilindungi oleh hukum. Tidak seorang pun dapat dirampas hak hidupnya secara sewenang-wenang. Lalu dalam pasal 8 angka 1 disebutkan tidak seorangpun dapat diperbudak; perbudakan dan perdagangan budak dalam segala bentuknya harus dilarang.

Instrumen Hukum Internasional telah melarang perbudakan dan sekarang ditinjau dari Instrumen Hukum Nasional, perbudakan juga dilarang. Hal ini ditandai di dalam Undang-undang Nomor 39 Tahun 1999 Tentang HAM, perbudakan dilarang di dalam Pasal 20 Ayat (1) dan (2). Dengan demikian bahwa kasus perbudakan di Tangerang ini merupakan suatu pelanggaran HAM dimana hal ini menyangkut dengan hak atas kebebasan pribadi para pekerja/buruh yang dirampas kemerdekaannya. Negara wajib melindungi setiap warga negara-nya agar terbebas dari praktik-praktik perbudakan semacam ini.

Dalam kasus yang terjadi di pabrik panci di Tangerang ini tentu saja telah melanggar Hak Asasi Manusia (HAM) para buruh yang bekerja di pabrik tersebut. Sangat penting untuk dipikirkan keselamatan para

7 Margaret McAuliffe deGuzman, 'The Road from Roma:The Developing Law of Crimes against Humanity" HumanFights Quorterlv.Vol 22. 2000. hlm 325-401. 
buruh saat menjalankan pekerjaannya. Demikian pula perlu diusahakan ketenangan dan kesehatan pekerja agar apa yang dihadapinya dalam pekerjaan dapat diperhatikan semaksimal mungkin, sehingga kewaspadaan dalam menjalankan pekerjaan itu tetap terjamin.

\section{KESIMPULAN}

Upah minimum propinsi (UMP) atau upah minimum kabupaten (UMK) sering diistilahkan dengan upah minimum. Upah ini pada prinsipnya diberikan kepada buruh sebagai jaringan pengaman (safety net). Kondisi anomali kebijakan pengupahan yang tidak hanya terjadi pada buruh dengan masa kerja dibawah 1 (satu) tahun, tetapi juga buruh dengan masa kerja diatas 1 (satu) tahun. Secara yuridis melanggar permenakertrans No. 01/MEN/1999 Pasal 25 ayat (1), pengusaha yang melanggar dan tidak memnuhi ketentuan dalam Pasal 14 ayat (1) dan (2) dipidana dengan pidana kurungan selama lamanya 3 (tiga) bulan atau denda setinggi-tingginya Rp 100.000,00 (seratus ribu rupiah).

Upah buruh yang tidak sesuai dengan standar UMP sdan UMK sangat dilarang keras oleh Pasal 90 ayat (1) UU No. 13 Tahun 2003 yang menegaskan bahwa "pengusaha dilarang membayar upah lebih rendah dari upah minimum..." kondisi demikian tentunya sangat merugikan kehidupan buruh dan keluarganya yang dengan upah minimum saja tidak mampu memenuhi kehidupannya baik itu makanan dan minuman, sandang, perumahan, pendidikan, kesehatan, rekreasi, maupun jaminan hari tua.

Kebijakan pemerintah dibidang pengupahan dilatar belakangi oleh permasalahan pengupahan yang selalu muncul yang dipicu terjadinya konflik kepentingan antara pengusaha dan pekerja.msalag pokok pengupana meliputi: rendahnya upah bagi pekerja bawah, kesenjangan upah terendah dan tertinggi, bervariasinya komponen upah, tidak jelasnya hubungan antara upah dan produktivitas. ${ }^{8}$

Dalam kasus yang terjadi di pabrik panci di Tangerang ini tentu saja telah melanggar Hak Asasi Manusia (HAM) para buruh yang bekerja di pabrik tersebut. Sangat penting untuk dipikirkan keselamatan para buruh saat menjalankan pekerjaannya. Demikian pula perlu diusahakan ketenangan dan kesehatan pekerja agar apa yang dihadapinya dalam pekerjaan dapat diperhatikan semaksimal mungkin, sehingga kewaspadaan dalam menjalankan pekerjaan itu tetap terjamin, ini juga dilakukan untuk menjamin perlindungan para perkerja sekaligus dalam bidang yang lain, seperti pengakuan hak asasi mansia, perlindungan fisik serta social dan ekonomi.

8 Pranoto iskandar. "Tindak Penyiksaan dan Hukum Internasional". Jurnal Ilmu Hukum Pandecta. Vol.6. No.2.2011. hlm 48. 


\section{REFERENSI}

\section{Undang-Undang:}

Undang-Undang Nomor 13 Tahun 2003 Tentang Ketenagakerjaan.

Undang-undang Nomor 39 Tahun 1999 Tentang Hak Asasi Manusia.

\section{Buku:}

Abdul hakim, Aspek hukum pengupahan berdasarkan UU no 13 tahun 2003, Bandung: PT Citra Aditya. 2006.

Uwiyono, Aloysius., dkk. Asas-Asas Hukum Perburuhan. Jakarta: PT. RajaGrafindo Persada. 2014.

Kartasapoetra, g. dan Rience Indraningsih, Pokok-pokok Hukum Perburuhan. Cet. 1. Bandung: Armico Bandung.1982.

Asikin, Zainal., dkk. Dasar-dasar Hukum Perburuhan. Jakarta: PT. RajaGransindo Persada. 2012.

\section{Jurnal:}

Widyawati, Anis. "Kajian Hukum Internasional Terhadap HAM". Jurnal Ilmu Hukum Pandecta Vol. 2, no. 2. 2008.

Supriyanto, Bambang Heri."Penegakkan Hukum Mengenai Hak Asasi Manusia (HAM) Menurut Hukum Positif di Indonesia". Jurnal AlAzhar Indonesia Seri Pranata Sosial Vol. 2, No. 3. 2014.

Margaret McAuliffe deGuzman, 'The Road from Roma:The Developing Law of Crimes against Humanity" HumanFights Quorterlv.Vol 22. 2000. Hal 335-403.

Iskandar, Pranoto. "Tindak Penyiksaan dan Hukum Internasional". Jurnal Ilmu Hukum Pandecta. Vol.6. No.2.2011. 